\title{
Activators of the Nuclear Hormone Receptors PPAR $\alpha$ and FXR Accelerate the Development of the Fetal Epidermal Permeability Barrier
}

\author{
Karen Hanley, ${ }^{\star \|}$ Yan Jiang, ${ }^{\star \mid}$ Debra Crumrine, ${ }^{\star \|}$ Nathan M. Bass, ${ }^{\ddagger}$ Renaissance Appel, ${ }^{\ddagger}$ Peter M. Elias, ${ }^{\star \|}$ Mary L. Williams, ${ }^{\S \|}$ \\ and Kenneth R. Feingold ${ }^{* * \mid \pi}$ \\ $*$ Department of Dermatology, ${ }^{\ddagger}$ Department of Medicine, and ${ }^{\S}$ Department of Pediatrics, University of California, San Francisco, \\ California 94143; and the $\|^{D e r m a t o l o g y}$ and "Medical Services, Department of Veterans Affairs Medical Center, San Francisco, \\ California 94121
}

\begin{abstract}
Members of the superfamily of nuclear hormone receptors which are obligate heterodimeric partners of the retinoid $X$ receptor may be important in epidermal development. Here, we examined the effects of activators of the receptors for vitamin $\mathrm{D}_{3}$ and retinoids, and of the peroxisome proliferator activated receptors (PPARs) and the farnesoid X-activated receptor (FXR), on the development of the fetal epidermal barrier in vitro. Skin explants from gestational day 17 rats (term is $22 \mathrm{~d}$ ) are unstratified and lack a stratum corneum (SC). After incubation in hormone-free media for 3-4 d, a multilayered SC replete with mature lamellar membranes in the interstices and a functionally competent barrier appear. 9-cis or all-trans retinoic acid, 1,25 dihydroxyvitamin $\mathrm{D}_{3}$, or the PPAR $\gamma$ ligands prostaglandin $\mathrm{J}_{2}$ or troglitazone did not affect the development of barrier function or epidermal morphology. In contrast, activators of the PPAR $\alpha$, oleic acid, linoleic acid, and clofibrate, accelerated epidermal development, resulting in mature lamellar membranes, a multilayered SC, and a competent barrier after $2 \mathrm{~d}$ of incubation. The FXR activators, all-trans farnesol and juvenile hormone III, also accelerated epidermal barrier development. Activities of $\beta$-glucocerebrosidase and steroid sulfatase, enzymes previously linked to barrier maturation, also increased after treatment with PPAR $\alpha$ and FXR activators. In contrast, isoprenoids, such as nerolidol, cis-farnesol, or geranylgeraniol, or metabolites in the cholesterol pathway, such as mevalonate, squalene, or 25-hydroxycholesterol, did not alter barrier development. Finally, additive effects were observed in explants incubated with clofibrate and farnesol together in suboptimal concentrations which alone did not affect barrier development. These data indicate a putative physiologic role for PPAR $\alpha$ and FXR in epidermal barrier development. (J. Clin. Invest. 1997. 100:705-712.) Key words: stratum corneum - farnesol • RXR • juvenile hormone $\cdot$ clofibrate
\end{abstract}

\section{Introduction}

Extracellular lipids in the stratum corneum (SC), ${ }^{1}$ the outermost layer of the epidermis, provide a hydrophobic seal be-

Address correspondence to Dr. Kenneth R. Feingold, Metabolism Service (111F), Department of Veterans Affairs Medical Center, 4150 Clement Street, San Francisco, CA 94121. Phone: 415-750-2005; FAX: 415-750-6927.

Received for publication 25 February 1997 and accepted in revised form 24 April 1997.

The Journal of Clinical Investigation

Volume 100, Number 3, August 1997, 705-712

http://www.jci.org tween the organism's interior and the xeric external environment $(1,2)$, a critical requirement for terrestrial life. The SC also provides the initial defense against microbial invasion, ingress of xenobiotics, UV light, and physical trauma. Because the epidermal barrier matures late in intrauterine development, i.e., during the third trimester, very premature infants lack a competent barrier, contributing to their morbidity and mortality (3-5).

Lipids are delivered to the SC by the exocytosis of lamellar bodies from granular cells, and these lipids are subsequently processed and reorganized into a continuous matrix of lamellar unit structures, characteristic of a mature SC and a competent barrier to transepidermal water loss $(1,2,6)$. Our studies in fetal rats have shown, both in utero and in a skin explant model, that the formation of a competent barrier by day 21 of gestation coincides with the appearance of morphologically mature, extracellular lamellar membranes in the $\operatorname{SC}(7,8)$. Several hormones, including glucocorticoids, estrogen, and thyroid hormone, the actions of which are mediated by nuclear receptors, accelerate SC and barrier development in these models, and induce increased levels of lipid metabolic enzymes which are closely associated with barrier maturation (8-12).

The glucocorticoid and estrogen receptors belong to a subgroup of the nuclear receptor superfamily of transcription factors which function as ligand-induced homodimers (for review see reference 13). Another subgroup, which includes the vitamin $D$ receptor, thyroid hormone receptor, retinoic acid receptor (RAR), and the peroxisome proliferator-activated receptors (PPARs), requires heterodimerization with the retinoid $\mathrm{X}$ receptor (RXR) for effective DNA binding $(14,15)$. Recent studies have shown that the retinoid receptors are important in epidermal development, e.g., overexpression of a dominant negative RAR mutant ( $\alpha$ subunit) in basal cells results in a thin epidermis and dry, scaly skin (16), whereas overexpression in suprabasal cells results in the absence of extracellular SC membranes and an incompetent barrier $(17,18)$. These effects can be attributed to the ability of the truncated RAR to bind RXR and form transcriptionally inactive heterodimers, thereby subverting the activity of RXR and its partners.

In addition to RAR, other members of the RXR group of nuclear receptors, which may influence epidermal development, include the receptors for thyroid hormone and 1,25dihydroxyvitamin $\mathrm{D}_{3}$, and the PPARs (subtypes $\alpha, \delta$, and $\gamma$ ) (19-21). The PPARs are activated by a variety of fatty acids and arachidonic acid metabolites, as well as by hypolipidemic agents, such as clofibrate (19-21). The $\alpha$ isoform plays a role in

1. Abbreviations used in this paper: FXR, farnesoid X-activated receptor; JH III, juvenile hormone III; PPAR, peroxisome proliferatoractivated receptor; RA, retinoic acid; RAR, RA receptor; RXR, retinoid $\mathrm{X}$ receptor; $\mathrm{SC}$, stratum corneum. 
the regulation of lipid metabolism in liver, intestine, and kidney, while the $\gamma$ subtype is involved primarily in the regulation of adipocyte differentiation (19-22). The $\delta$ isoform is widely expressed, but its function is the least understood. Another newly described receptor, which is an obligate partner of the RXR, is the farnesoid X-activated receptor (FXR) (23). This receptor is activated by farnesol and juvenile hormone III ( $\mathrm{JH}$ III) (23). JH III, like farnesol, is a metabolite of farnesyl pyrophosphate, an important intermediate in the cholesterol biosynthetic pathway. FXR is expressed in several tissues which are active in sterologenesis, such as liver, gut, adrenal gland, and kidney (23). Since both fetal and adult epidermis are highly active sites of cholesterol and fatty acid synthesis (24, 25 ), it is likely that they generate a variety of endogenous activators of both FXR and PPAR.

In earlier studies, we showed that one ligand for the RXRinteracting family, thyroid hormone, accelerates fetal barrier development (8). In this study, we determined whether other ligands or activators of the RXR superfamily of nuclear receptors accelerate fetal skin maturation, using a previously described model in which epidermal development in fetal skin explants morphologically and functionally mirror the kinetics of developmental changes that occur in utero (8). We report here that activators of both FXR and PPAR $\alpha$ accelerate the formation of a mature SC and functional epidermal permeability barrier, while ligands for the RAR, RXR, PPAR $\gamma$, and vitamin D receptor had no effect.

\section{Methods}

Organ culture model and measurement of barrier function. Timed pregnant Sprague-Dawley rats (plug date $=$ day 0 ) were obtained from Simonsen Laboratories (Gilroy, CA) and fetuses were delivered prematurely on day 17. Full-thickness flank skin was excised from fetal rats and incubated dermis-side down on collagen membrane inserts ( $3 \mu \mathrm{m}$ pore size), as described previously (8). It was not possible to obtain intact skin from animals of an earlier gestational age. Epidermal water loss was measured gravimetrically in explants after $2 \mathrm{~d}$ of incubation, and reported as $\mathrm{mg}$ water $\mathrm{lost} / \mathrm{mm}^{2} / \mathrm{h}$, as previously described (8). Longer incubations were not carried out because as described previously (8) by $3 \mathrm{~d}$ there is variable formation of a competent barrier. Prostaglandin $\mathrm{J}_{2}$ (15-deoxy- $\Delta^{12,14}$-prostaglandin $\mathrm{J}_{2}$ ) was obtained from Cayman Chemical Co. (Ann Arbor, MI). Troglitazone and WY14,643 [pirinixic acid; 4-chloro-6-(2,3-xylidino)-2-pyrimidinyl thioacetic acid] were from Parke-Davis Pharmaceutical and Chemsyn Science Labs. (Lenexa, KS), respectively. Nerolidol, cis-farnesol, and geranylgeraniol were kindly provided by Drs. S. Jackson and P. Edwards (University of California, Los Angeles), and 1,25-dihydroxy vitamin $\mathrm{D}_{3}$ by Dr. D. Bikle (University of California, San Francisco). All other compounds were from Sigma Chemical Co. (St. Louis, MO). Fatty acids were added to the medium bound to $0.5 \%$ (wt/vol) BSA. Isoprenoids and 25-hydroxycholesterol were added in ethanol, and clofibric acid ( $p$-chlorophenoxyisobutyric acid) and JH III were added in DMSO. Control explants were incubated in the presence of the appropriate vehicle ( $\leq 0.1 \% \mathrm{DMSO}$ or ethanol, and/or $\leq 0.5 \% \mathrm{BSA})$.

Light and electron microscopy. Samples for light microscopy were fixed in modified Karnovsky's solution, plastic-embedded, and 0.5$\mu \mathrm{m}$ sections were stained with Toluidine blue. Samples for electron microscopy were minced into $1-\mathrm{mm}^{3}$ pieces, fixed in modified Karnovsky's fixative, and postfixed in ruthenium tetroxide as described (7). Ultrathin sections were stained with uranyl acetate and lead citrate and examined using an electron microscope (10A; Carl Zeiss, Inc., Thornwood, NY) operated at $60 \mathrm{kV}$.

Tissue preparation for enzyme assays. Epidermis was separated from dermis after incubation in $10 \mathrm{mM}$ EDTA in $\mathrm{Ca}^{2+}$ - and $\mathrm{Mg}^{2+}$ - free PBS, $\mathrm{pH} 7.4$, at $37^{\circ} \mathrm{C}$ for $30-40 \mathrm{~min}$. The tissues were then minced, and homogenized on ice $(3 \times 15 \mathrm{~s}$ with a Polytron homogenizer, followed by $2 \times 10$ s sonication at $35 \%$ power) either in PBS containing $0.1 \mathrm{mM}$ PMSF and $0.1 \%$ Triton X-100 (for $\beta$-glucocerebrosidase) or in $10 \mathrm{mM}$ Tris ( $\mathrm{pH} 7.5$ ) containing $0.15 \mathrm{M}$ sucrose and $2 \mathrm{mM}$ EDTA (for steroid sulfatase). $\beta$-glucocerebrosidase activity was measured in the supernatant after centrifugation at $10,000 \mathrm{~g}$ for $15 \mathrm{~min}$ at $4^{\circ} \mathrm{C}$. Steroid sulfatase activity was measured in the microsomal fraction resulting from a $10,000 \mathrm{~g}$ centrifugation $\left(10 \mathrm{~min}, 4^{\circ} \mathrm{C}\right)$ followed by $60 \mathrm{~min} 100,000 \mathrm{~g}$ ultracentrifugation $\left(4^{\circ} \mathrm{C}\right)$.

$\beta$-Glucocerebrosidase and steroid sulfatase assays. $\beta$-glucocerebrosidase activity was assayed using the synthetic substrate 4-MUG as described previously (11). Briefly, assays were performed in $5 \mathrm{mM}$ sodium taurocholate in citrate-phosphate buffer $(\mathrm{pH} 5.6)$ with $0.5 \mathrm{mM}$ 4-MUG for $60 \mathrm{~min}$ at $37^{\circ} \mathrm{C}$, with a final assay volume of $100 \mu \mathrm{l}$, and protein concentration of $1-2 \mathrm{mg} / \mathrm{ml}$. The reaction was terminated with $2 \mathrm{ml}$ of carbonate-bicarbonate buffer ( $\mathrm{pH}$ 10.5). The fluorescence was then measured at $360 \lambda$ (excitation) and $450 \lambda$ (emission) and compared with a standard (4MU) curve.

Steroid sulfatase activity was measured as described previously (12). Briefly, $100 \mu \mathrm{g}$ of microsomal protein in $0.1 \mathrm{M}$ Tris containing $5.6 \mathrm{mM}$ glucose (pH 7.4) was incubated with $15 \mu \mathrm{M}\left[{ }^{3} \mathrm{H}\right]$ dihydroepiandrosterone sulfate $(15 \mu \mathrm{Ci})$ in a final volume of $1.1 \mathrm{ml}$. The product, $\left[{ }^{3} \mathrm{H}\right]$ dihydroepiandrosterone, was extracted with benzene and an aliquot counted by scintillation spectrophotometry.

Statistical analysis. Statistical evaluation was performed using a Student's $t$ test.

\section{Results}

Ligands/activators of $R X R$ heterodimers which do not accelerate barrier development. We first sought to determine whether ligands or activators of members of the nuclear receptor superfamily, which dimerize with the RXR, alter the kinetics of barrier development. Skin explants from gestational day 17 rats were incubated in the presence of either various activators or vehicle, and transepidermal water loss was measured after $2 \mathrm{~d}$.

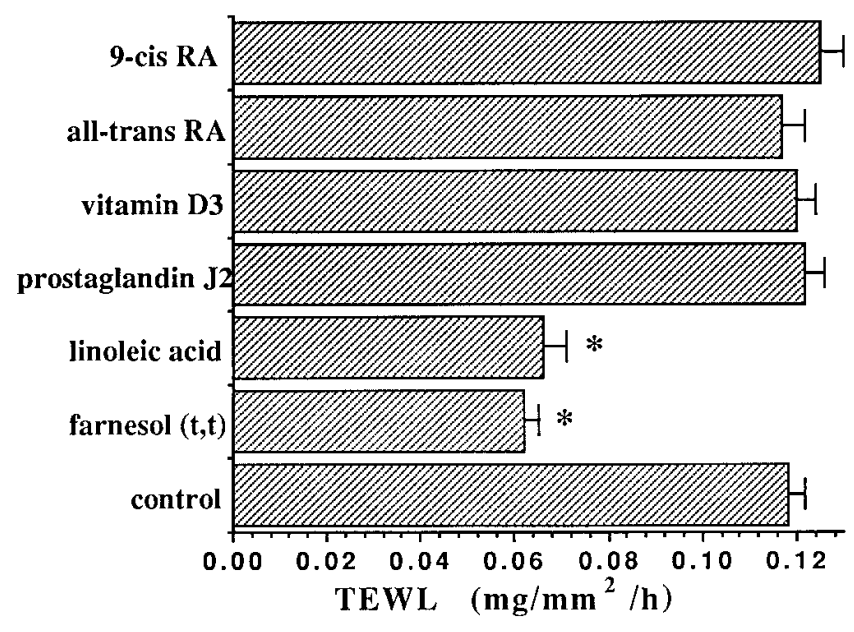

Figure 1. Effect of activators of the RXR superfamily on barrier development in vitro. Full-thickness skin explants from gestational day 17 rats were incubated for $2 \mathrm{~d}$ in the presence of either $1 \mu \mathrm{M}$ all-trans RA, $1 \mu \mathrm{M}$ 9-cis RA, $1 \mu \mathrm{M}$ 1,25 dihydroxy vitamin D3, $10 \mu \mathrm{M}$ prostaglandin $\mathrm{J}_{2}, 30 \mu \mathrm{M}$ linoleic acid, or in control media, and transepidermal water loss was measured at the termination of the experiment, as described in Methods. Results are presented as mean \pm SEM of two separate experiments $(n=8) . * P<0.005$. 
Earlier studies have shown that full-thickness skin from gestational day 17 rats, after $2 \mathrm{~d}$ in culture, exhibits lamellar bodies in the granular cells, and secreted lamellar material in the SC interstices, but, like day 19 rat skin in utero, the SC lacks mature lamellar membrane structures and a competent barrier is not present (8). In contrast, an SC with barrier function equivalent to that observed in mature epidermis normally forms by day 4 in culture, corresponding to day 21 in utero (8). As shown in Fig. 1, 9-cis retinoic acid (RA) (RXR ligand), alltrans RA (RAR or RXR ligand), 1,25-dihydroxyvitamin $\mathrm{D}_{3}$ (ligand for vitamin $\mathrm{D}$ receptor), or prostaglandin $\mathrm{J}_{2}$ (PPAR $\gamma$ ligand) had no significant effect on barrier development. Furthermore, no effect on the rate of barrier development was observed with either 9-cis or all-trans RA, or 1,25 dihydroxyvitamin $D_{3}$, in concentrations ranging from $1 \mathrm{nM}$ to $1 \mu \mathrm{M}$ (data not shown). These data suggest that activators of the retinoid receptors, vitamin D receptor, and PPAR $\gamma$ alone do not accelerate fetal barrier development.

Activators of PPAR $\alpha$ accelerate barrier development. Whereas retinoids and vitamin $\mathrm{D}_{3}$ did not accelerate barrier development, activators of the PPAR $\alpha$ markedly stimulated barrier formation. For example, water loss rates declined markedly in explants incubated in $30 \mu \mathrm{M}$ linoleic acid for $2 \mathrm{~d}$ (Fig. $1 ; P<0.005, n=8$ ). The three PPAR subtypes, $\alpha, \delta$, and $\gamma$, are pharmacologically distinct, and are differentially activated (19-21, 26, 27). Thus, while linoleic acid is a potent activator of the PPAR $\alpha$, it can also activate the $\delta$ isoform (21). To determine whether the acceleration of barrier development by linoleic acid is likely to be PPAR $\alpha$-mediated, we also tested a variety of other PPAR activators (Fig. 2). While several of these agents (oleic acid, WY 14,643, and ETYA), like linoleic acid, may also activate the $\delta$ isoform, clofibrate activates only the $\alpha$ isoform (21). As shown in Fig. 2, activators of the PPAR $\alpha$, such as the peroxisome proliferators, clofibrate, WY 14,643, and oleic acid, all significantly accelerated epidermal barrier development. Although toxic effects of the PPAR $\alpha$ activator

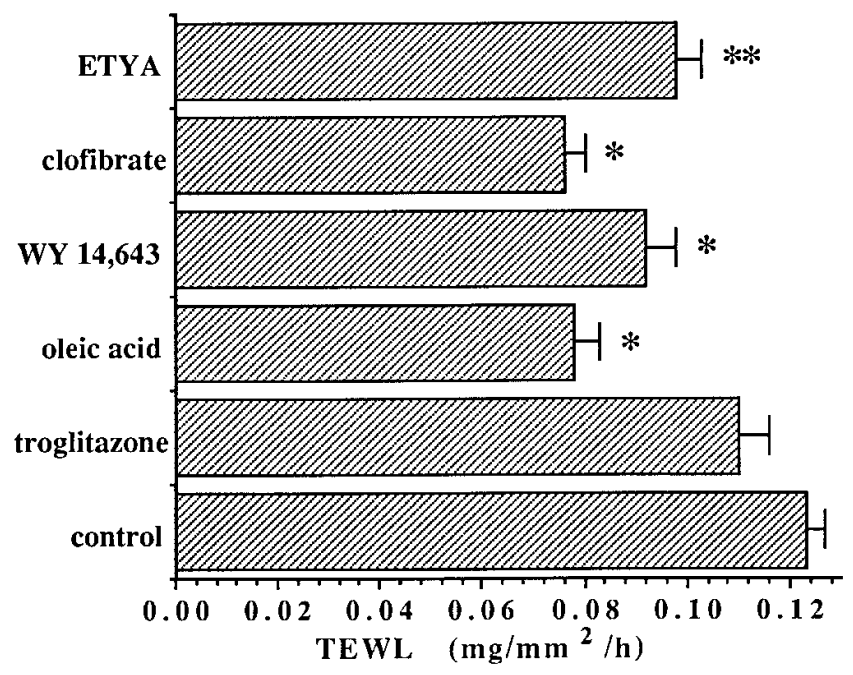

Figure 2. Effect of PPAR activators on barrier development in vitro. Explants were incubated for $2 \mathrm{~d}$ in the presence of $100 \mu \mathrm{M} 5,8,11$ eicosatetraynoic acid (ETYA), $300 \mu \mathrm{M}$ clofibrate, $100 \mu \mathrm{M}$ WY $14,643,300 \mu \mathrm{M}$ oleic acid, $10 \mu \mathrm{M}$ troglitazone, or in control media, and water was loss measured as in Fig. 1. Results are presented as mean \pm SEM of two separate experiments $(n=8) . * P<0.005$. arachidonic acid precluded study, the synthetic arachidonic acid analog, ETYA (5,8,11,14-eicosatetrayonic acid), also a known PPAR $\alpha$ activator $(19,21)$, induced significant acceleration of barrier development. In contrast, the PPAR $\gamma$ activator troglitazone, like prostaglandin $\mathrm{J}_{2}$, did not accelerate barrier formation. Taken together, these data suggest that activators of PPAR $\alpha$, but not $\operatorname{PPAR} \gamma$, accelerate epidermal barrier development.

Activators of FXR accelerate barrier development. We next assessed whether activators of FXR would also accelerate barrier development. As seen in Fig. 1, all-trans farnesol significantly accelerated barrier ontogenesis $(P<0.005, n=8)$. To determine whether the effect on barrier development by farnesol, an isoprenoid product of the mevalonate pathway (28), might be FXR-mediated, we also tested the effects of a variety of cholesterol analogs and precursors, as well as other isoprenoids, including the known FXR activator, JH III (23), on the kinetics of barrier development. As shown in Fig. 3, JH III, an FXR activator not present in mammalian cells, significantly accelerated barrier formation $(P<0.005, n=6)$. In contrast, neither mevalonate, 25-OH cholesterol, nor squalene accelerated barrier formation (Fig. 3). Similarly, incubation of explants with the isoprenols, geranylgeraniol, cis-farnesol, or nerolidol, did not significantly affect barrier function (Fig. 3). These results suggest that the effect of farnesol on barrier formation is unlikely to be related to its role as a precursor to cholesterol or other isoprenoid products, and that the acceleration of barrier development by farnesol and JH III is FXR mediated.

The effects of farnesol and clofibrate are additive. We next examined dose responses for the PPAR $\alpha$ activators clofibrate, oleic acid, and linoleic acid, and for the FXR activators farnesol and JH III. As shown in Fig. $4 A$, the acceleration of barrier formation by clofibrate and oleic acid is dose dependent, with maximal effects seen with $300 \mu \mathrm{M}$ and half-maximal effects with $\sim 150 \mu \mathrm{M}$. Linoleic acid (Fig. 4, $A$, inset) also accelerates

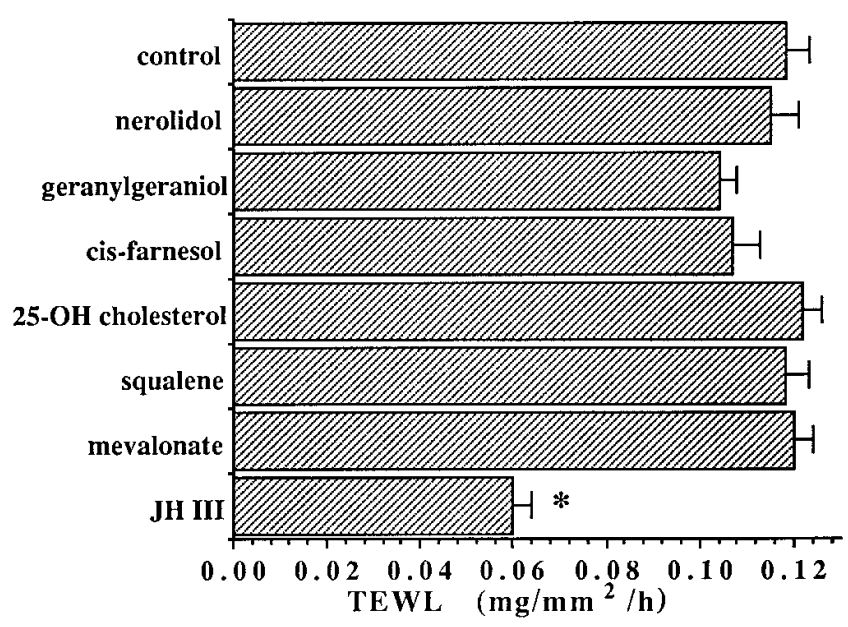

Figure 3. Effect of FXR activators and isoprenoid precursors and metabolites on barrier development in vitro. Explants were incubated for $2 \mathrm{~d}$ in the presence of $100 \mu \mathrm{M}$ nerolidol, geranyl geraniol, cis-farnesol, 25-hydroxy cholesterol, or squalene, or $200 \mu \mathrm{M}$ mevalonate, or in control media, and water loss was measured as in Fig. 1. Results are presented as mean \pm SEM of two separate experiments $(n=8)$. $* P<0.005$. 

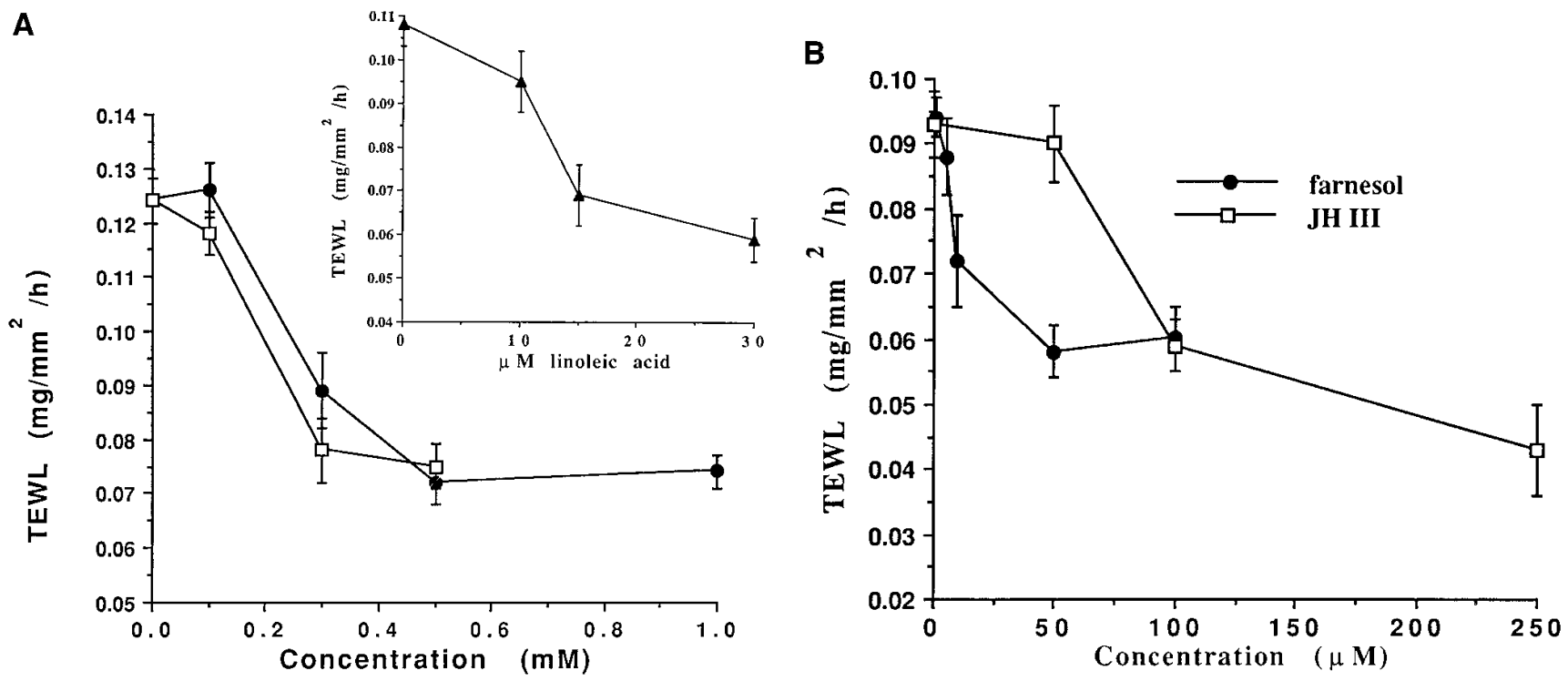

Figure 4. Dose response of PPAR $\alpha$ or FXR activators on barrier development in vitro. Fetal skin explants were incubated in the presence of increasing concentrations of clofibrate $(10-1,000 \mu \mathrm{M})(A$, closed circles $)$, oleic acid $(10-500 \mu \mathrm{M})(A$, open squares $)$, linoleic acid $(10-30 \mu \mathrm{M})(A$, inset), farnesol (1-100 $\mu \mathrm{M})(B$, closed circles), or JH III (50-250 $\mu \mathrm{M})(B$, open squares) for $48 \mathrm{~h}$. Transepidermal water loss was measured as described in Methods. Results are presented as mean $\pm \operatorname{SEM}(n=4)$. Similar results were obtained in two independent experiments.

barrier formation in a dose-dependent manner, but it was $>10$-fold more potent than clofibrate or oleic acid, with maximal and half-maximal effects seen with 20 and $15 \mu \mathrm{M}$, respectively. Fig. $4 B$ shows the dose responses for farnesol and $\mathrm{JH}$ III. In these experiments, farnesol was more potent than $\mathrm{JH}$ III (farnesol: 50 and $20 \mu \mathrm{M}$, JH III: 250 and $100 \mu \mathrm{M}$, maximal and half-maximal effective concentrations, respectively). The micromolar concentrations of the fatty acids and farnesol used here are consistent with their estimated plasma or intracellular concentrations and with levels known to activate PPAR $\alpha$ or FXR $(19,21,23)$, suggesting that these lipids may be endogenous activators of these receptors.

We next sought to determine whether 9-cis RA, the ligand for the RXR, together with PPAR $\alpha$ or FXR activators might exert synergistic or additive effects on barrier development. No effect on either barrier function or epidermal morphologic maturation was observed with 9-cis RA $(1 \mu \mathrm{M})$ in combination with either clofibrate $(100 \mu \mathrm{M})$ or farnesol $(10 \mu \mathrm{M})$ (data not shown), doses of the PPAR $\alpha$ and FXR activators which alone did not accelerate barrier formation (see Fig. 4, $A$ and $B$ ). In contrast, when clofibrate $(100 \mu \mathrm{M})$ and farnesol $(10 \mu \mathrm{M})$ were provided together in suboptimal concentrations, barrier development was significantly accelerated (Fig. $5 A$ ). However, incubation of explants with both activators at their maximally effective concentrations (farnesol and clofibrate, 50 and $300 \mu \mathrm{M}$, respectively) did not further accelerate barrier development over either agent given alone (Fig. $5 \mathrm{~B}$ ). The additive effects of clofibrate and farnesol at suboptimal doses suggest that both classes of activators may utilize a similar activation pathway. Furthermore, the lack of synergy between 9-cis RA and either clofibrate or farnesol suggests either that RXR activation is not required, or that sufficient endogenous RXR activators are already present.

PPAR $\alpha$ or FXR activators stimulate epidermal structural maturation. To examine the effects of PPAR $\alpha$ and FXR acti- vators on epidermal maturation, we next evaluated the morphology of explants incubated in control media or in media containing PPAR $\alpha$ or FXR activators. As shown in Fig. 6 , the epidermis in control explants after $2 \mathrm{~d}$ in culture lacked a multilayered stratum granulosum or a distinct SC, corresponding to day 19 of gestation $(7,8)$. Similar to the functional results noted above, neither 1,25 dihydroxyvitamin $\mathrm{D}_{3}$, all-trans RA, nor 9-cis RA altered structural maturation (compare with Fig. 1). In contrast, both a multilayered stratum granulosum and SC were observed in explants treated with either clofibrate $(300 \mu \mathrm{M})($ Fig. 6 B) or JH III $(100 \mu \mathrm{M})($ Fig. 6 C). Similar results were observed in explants treated with oleic acid $(300 \mu \mathrm{M})$, linoleic acid $(30 \mu \mathrm{M})$, and farnesol $(50 \mu \mathrm{M})$ (not shown). In contrast, explants incubated with either clofibrate or farnesol in suboptimal concentrations did not exhibit a distinct SC and were morphologically indistinguishable from controls (data not shown).

We next compared the ultrastructural maturation of the outer epidermis using ruthenium tetroxide postfixation to delineate SC membranes in explants exposed to PPAR $\alpha$ or FXR activators (Fig. 7). Multiple arrays of mature lamellar membrane unit structures fill the extracellular domains of the $\mathrm{SC}$ in clofibrate-treated (Fig. 7 A, arrows) or JH III-treated (Fig. $7 \mathrm{~B}$, arrows) explants. Similar acceleration of SC membrane deposition was observed in oleic acid-, linoleic acid-, or farnesoltreated explants (not shown). In contrast, the extracellular lamellae in the single layered SC in control explants were not yet organized into mature lamellar membranes (Fig. $7 \mathrm{C}$ ). Thus, stimulation of the functional development of the barrier is accompanied by accelerated epidermal stratification and the more rapid appearance of mature lamellar unit structures in the SC intercellular regions.

Clofibrate and JH III induce $\beta$-glucocerebrosidase and steroid sulfatase activities, enzymatic markers of barrier maturation. Earlier studies have demonstrated that epidermal $\beta$-glu- 

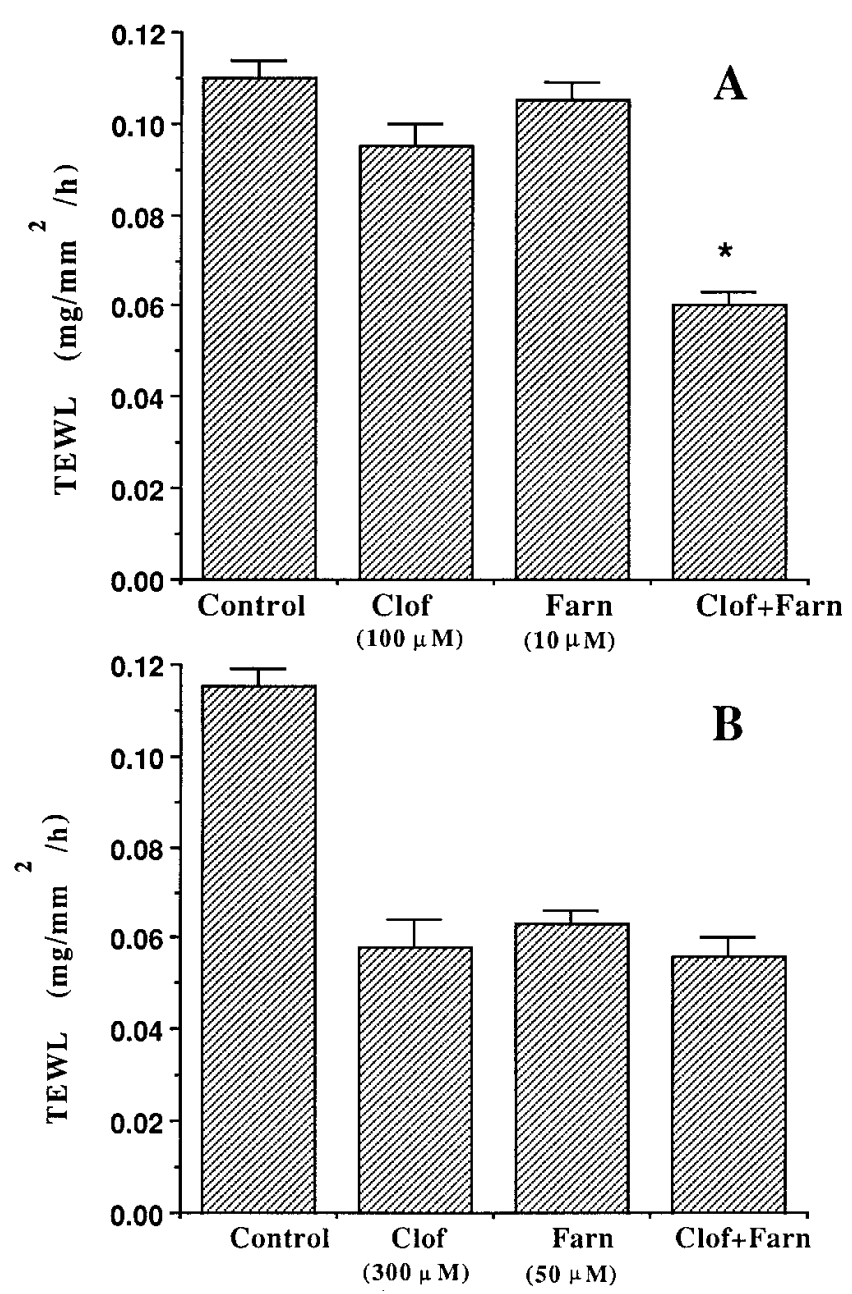

Figure 5. Effect of PPAR $\alpha$ and FXR activators alone and in combination on barrier development in vitro. Fetal skin explants were incubated for $2 \mathrm{~d}$ in the presence of suboptimal concentrations $(A)$ or optimal concentrations $(B)$ of clofibrate and farnesol, alone or in combination. Transepidermal water loss was measured at the termination of the experiment as described in Methods. Data represent the mean values of two experiments, $n=8,{ }^{*} P<0.01$ (clofibrate plus farnesol in comparison to control, and to clofibrate alone and to farnesol alone $[A])$.

cocerebrosidase activity increases during the final stages of barrier development in the rat in utero and in vitro, and that inhibition of this enzyme both prevents barrier formation and disrupts barrier homeostasis $(11,29)$. Moreover, hormones which accelerate epidermal barrier formation increase $\beta$-glucocerebrosidase activity in fetal skin explants (11). Likewise, steroid sulfatase activity also increases during the final stages of barrier formation and its activity also is stimulated by these hormones (12). To determine whether the activity of these two enzymes is affected by PPAR $\alpha$ or FXR activators, we incubated 17-d fetal rat skin explants for $2 \mathrm{~d}$ in the presence of clofibrate $(300 \mu \mathrm{M})$ or JH III $(100 \mu \mathrm{M})$ and measured enzyme activity. As shown in Table I, $\beta$-glucocerebrosidase activity was approximately twofold higher in treated explants than controls after $1(P<0.005, n=5)$ or $2 \mathrm{~d}(P<0.005, n=5)$. Moreover, steroid sulfatase was also increased significantly (1.6-fold over
Table I. Effects of PPAR $\alpha$ or FXR Activators on $\beta$-Glucocerebrosidase or Steroid Sulfatase Activity in Fetal Skin

\begin{tabular}{|c|c|c|c|}
\hline & & \multicolumn{2}{|c|}{ Activity } \\
\hline & & $\beta$-Glucocerebrosidase & Steroid sulfatase \\
\hline & & $\mathrm{nmol} / \mathrm{min} / \mathrm{mg}$ & $\mathrm{pmol} / \mathrm{h} / \mathrm{mg}$ \\
\hline \multicolumn{4}{|l|}{ 24-h incubation } \\
\hline & Control & $1.35 \pm 0.22$ & $5.99 \pm 0.80$ \\
\hline & Clofibrate & $* 2.97 \pm 0.30$ & $* 13.90 \pm 1.10$ \\
\hline & JH III & $* 2.89 \pm 0.20$ & $* 12.55 \pm 1.25$ \\
\hline \multicolumn{4}{|l|}{ 48-h incubation } \\
\hline & Control & $3.02 \pm 0.45$ & $8.75 \pm 0.91$ \\
\hline & Clofibrate & $* 5.35 \pm 0.89$ & $* 22.51 \pm 2.60$ \\
\hline & JH III & $* 5.20 \pm 0.62$ & $* 18.23 \pm 2.35$ \\
\hline
\end{tabular}

Explants were incubated for 24 or $48 \mathrm{~h}$ in the presence of $300 \mu \mathrm{M}$ clofibrate, $100 \mu \mathrm{m} \mathrm{JH} \mathrm{III,} \mathrm{or} \mathrm{vehicle} \mathrm{alone.} \mathrm{Enzyme} \mathrm{activity} \mathrm{was} \mathrm{measured} \mathrm{as}$ described in Methods. Results are presented as mean \pm SEM and represent two separate experiments. ${ }^{*} P \leq 0.005$ compared with controls of same time point, $n=5$.

controls after $1 \mathrm{~d}$ of incubation, $P<0.01, n=5$, and 2.5 -fold after $2 \mathrm{~d}, P<0.005, n=5)$. These data demonstrate that both clofibrate and JH III accelerate the developmental increases in activity of two lipid metabolic enzymes associated with barrier formation.

\section{Discussion}

The epidermal permeability barrier forms late in gestation. In earlier studies, we demonstrated that several hormones which act via nuclear receptors, notably glucocorticoids, thyroid hormone, and estrogen, accelerate barrier maturation (8-10). Yet, the role of hormonal ligands in normal barrier ontogenesis is not entirely clear, because fetal rat skin cultivated in vitro in hormone-free media develops a competent barrier following the same time course that is observed in utero (8). This observation prompted us to examine whether endogenous lipid activators of other nuclear hormone receptors might regulate barrier ontogenesis.

In this study, we have shown that activators of the PPAR $\alpha$ (oleic acid, linoleic acid, or clofibrate) and of the FXR (farnesol or JH III) accelerate barrier development, as evidenced by decreased transepidermal water loss, increased epidermal stratification, and the appearance of mature lamellae in the extracellular spaces of a multilayered SC by day 2 of culture. Additionally, PPAR $\alpha$ or FXR activators stimulate the activities of both $\beta$-glucocerebrosidase and steroid sulfatase, two key enzymes of mature SC function which are induced during the final stages of barrier ontogenesis $(11,12)$. Thus, functional, morphologic, and enzymatic markers of barrier development are accelerated by PPAR $\alpha$ or FXR activators. Moreover, several of these activators, e.g., oleic and linoleic acid and farnesol, are candidates as physiologic activators of these receptors. We have shown previously that adult epidermis is an extremely active site of cholesterol and fatty acid synthesis (25), rivaling the liver, gut, kidney, and steroidogenic tissues. Moreover, lipid synthesis is high in fetal rat epidermis immediately 

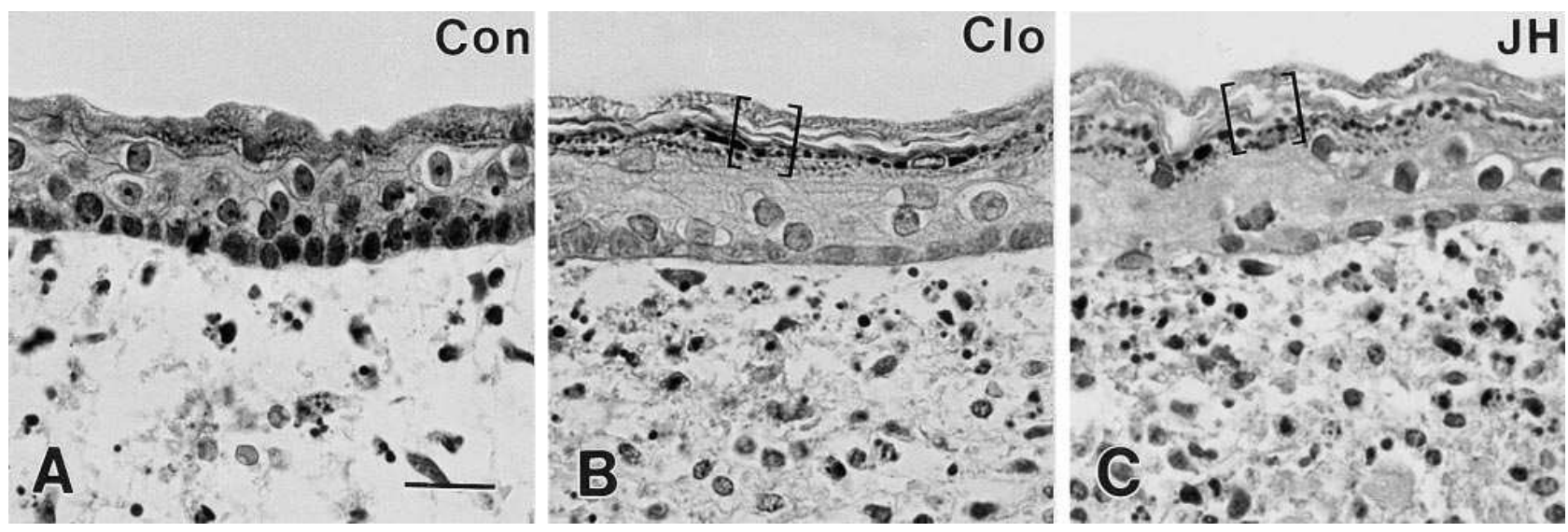

Figure 6. Effect of PPAR $\alpha$ or FXR activators on the morphology of developing fetal skin in vitro. Explants were epon-embedded and 0.5- $\mu \mathrm{m}$ sections were stained with Toluidine blue. Explants incubated for $2 \mathrm{~d}$ in control media (Con, $A$ ) exhibit a multilayered stratum spinosum, but the stratum granulosum and SC are not yet well-defined. $2 \mathrm{~d}$ of incubation in $300 \mu \mathrm{M}$ clofibrate $(C l o, B)$ results in the appearance of a multilayered stratum granulosum and SC (brackets). Similar results are seen in explants incubated for $2 \mathrm{~d}$ in $100 \mu \mathrm{M} \mathrm{JHIII}(\mathrm{JH}$, C). Results shown are representative of three separate experiments. Bar, $8 \mu \mathrm{m}$.

before the formation of a measurable barrier to water loss (24). Thus, significant levels of fatty acids, i.e., activators of PPAR $\alpha$, and isoprenoids, i.e., cholesterol biosynthetic metabolites which activate the FXR, are likely to be generated in fetal epidermis at the critical day 17-19 stage in barrier maturation.

Farnesol is an isoprenoid metabolite of farnesyl pyrophosphate, which is involved in protein isoprenylation and in the regulation of the rate-limiting enzyme of the cholesterogenic pathway, HMG CoA reductase $(30,31)$. Although farnesol inhibits phosphatidylcholine synthesis in human leukemia cells, leading to apoptosis $(32,33)$, and inhibits vasoconstriction in arteries (34), no effects of farnesol or its metabolites on skin have been described before our studies. Despite both the identification of FXR in several extracutaneous tissues and the

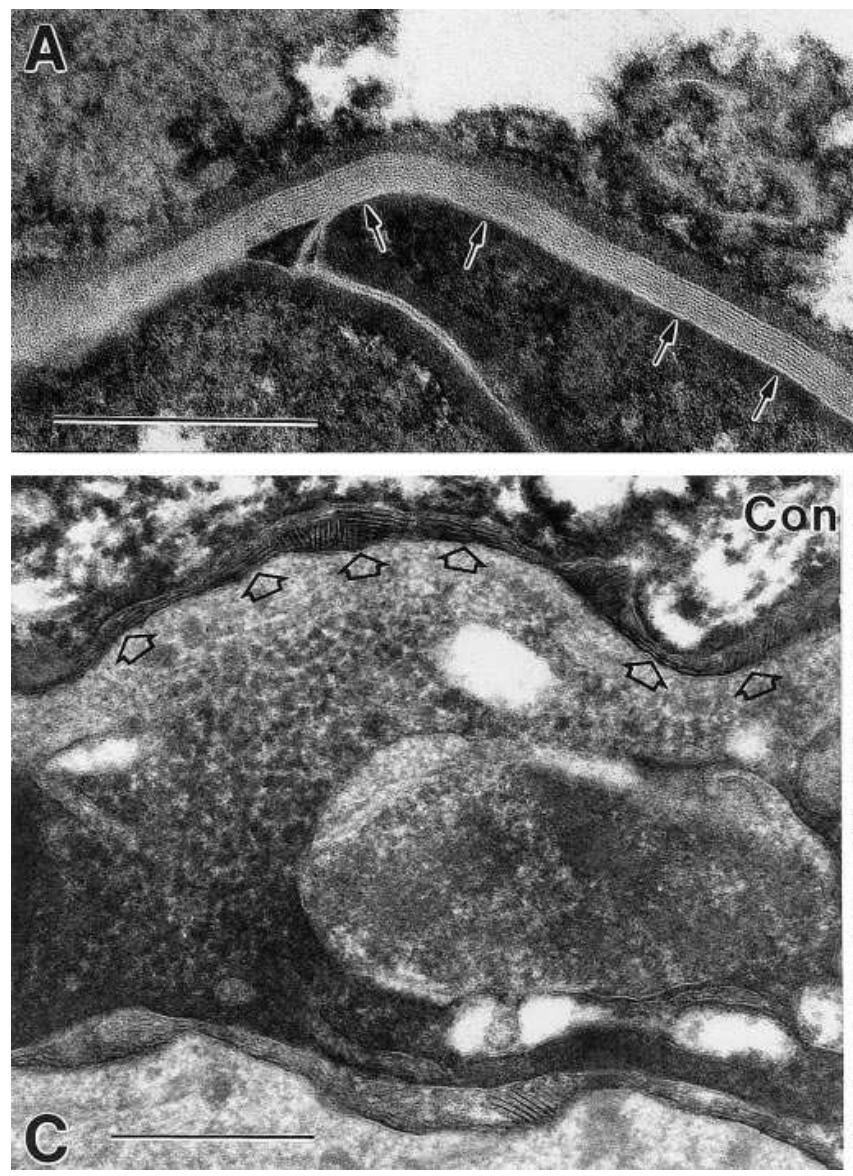

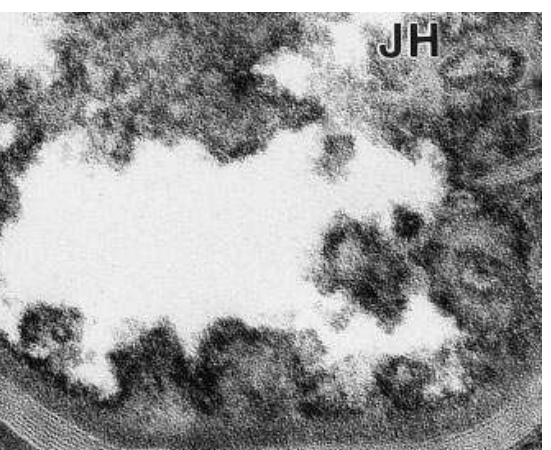

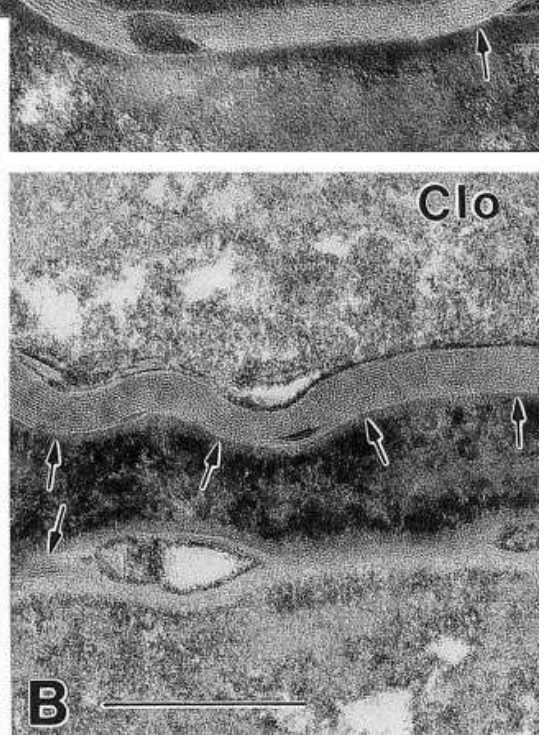

Figure 7. Effect of PPAR $\alpha$ and FXR activators on ultrastructural maturation of fetal epidermis in vitro. Ruthenium tetroxide postfixation reveals mature lamellar unit structures (closed arrows) in the extracellular spaces of the SC in JH III-treated $(A)$ or clofibrate-treated $(B)$ fetal skin explants. Mature lamellae are not present in the extracellular spaces of the $\mathrm{SC}$ in control explants $(C)$. Although secreted lamellar material (open arrows) is found in the SC interstices of control explants, it is not reorganized into mature structures. Bar, $0.25 \mu \mathrm{m}$. 
identification of certain of its activators, the actual ligands, as well as the function of this signaling pathway, remain unknown. We provide evidence here that the effects of farnesol on epidermal permeability barrier development may be FXR mediated, because: $(a)$ farnesol is a known activator of FXR (23); (b) JH III, a sesquiterpenoid which regulates insect development in concert with ecdysteroids, and which also activates FXR (23), also significantly accelerated epidermal barrier development in these studies; and finally, $(c)$ related isoprenoids, such as nerolidol and cis-farnesol, and cholesterol precursors, such as mevalonate, or metabolites, such as 25hydroxycholesterol, all of which do not activate the FXR, displayed no effects on barrier development. Thus, it is likely that the effects of farnesol and JH III on epidermal development are FXR-mediated rather than posttranscriptional, metabolic effects. The precise role of the FXR in barrier development awaits functional studies in which the FXR is either deleted or altered.

Other members of the RXR superfamily of nuclear hormone receptors appear to be important in fetal skin development. It has long been known that thyroid hormone stimulates markers of postnatal epidermal development in rodents such as incisor eruption and eye opening (35). Moreover, our laboratory has shown that thyroid hormone also accelerates fetal epidermal barrier ontogenesis (8). Furthermore, vitamin A and its analogues exhibit profound effects on fetal epidermal development $(36,37)$. Finally, recent studies have shown that overexpression of a mutated $\operatorname{RAR} \alpha$ in fetal murine skin results in aberrant epidermal development $(17,18)$.

In light of the above, it is somewhat surprising that neither all-trans RA, which activates the RAR, nor 9-cis RA, the natural ligand for RXR, had any effect on barrier development. Likewise, 1,25-dihydroxyvitamin $\mathrm{D}_{3}$, which exerts changes in epidermal differentiation and proliferation $(38,39)$, had no effect on barrier development. This lack of effects does not exclude a role for one or more of these compounds in epidermal development. Although explants are maintained in a serumand hormone-free medium, sufficient levels of endogenous vitamins A and/or D may be present in day 17 fetal skin to permit vitamin-dependent development to proceed. In addition, the principal effects of one or more of these vitamins could occur at an earlier or later time in gestation. Additionally, it is possible that this in vitro explant model does not precisely mirror all aspects of in utero ontogenesis. Although treatment with RA plus PPAR or FXR activators has been shown to synergistically induce gene expression in some experimental systems (23), we did not observe such synergism with the combination of retinoids and PPAR $\alpha$ or FXR activators. We did observe, however, additive effects by activators of PPAR $\alpha$ and FXR. Thus, clofibrate and farnesol, when added in concentrations which alone did not affect barrier development, together accelerated barrier development. Whether this reflects a common mechanism of action or a convergence of signaling pathways remains to be determined.

Although the genes regulated by FXR are yet to be identified, many of the genes regulated by PPARs are known to encode enzymes of lipid metabolism (20). Thus, PPAR $\alpha$ and FXR activators may regulate the generation of the lipid constituents of the barrier during fetal development. In these studies, we have shown that PPAR $\alpha$ and FXR activators induce expression of two lipid metabolic enzymes, $\beta$-glucocerebrosidase and steroid sulfatase, which are linked to barrier develop- ment and to SC homeostasis $(11,12,30)$. Whether these enzymes contain regulatory sequences for these transcription factors and are induced directly, or whether the activators stimulate the expression of these enzymes indirectly remains to be determined. Finally, the role of these nuclear receptor activators in the regulation of barrier homeostasis in the adult also remains to be determined.

It is noteworthy that PPAR $\alpha$ activators may also regulate surfactant formation in the lung, a tissue with many similarities to the skin. Both lung and skin provide a lipid-enriched interface between an aqueous and gaseous environment; both mature during precisely the same late gestational period; and both are developmentally accelerated by glucocorticoids, thyroid hormone, or estrogen (40-42). Pertinently, both organs rely on a lamellar organelle for lipid storage and secretion, contained within the granular cells in epidermis and in the alveolar type II cells in the lung. In the adult rat, clofibrate treatment results in increased quantities of lamellar bodies in alveolar type II cells (43). Interestingly, glucocorticoids, which accelerate both lung and epidermal development, strongly induce PPAR $\alpha$ gene expression in liver at the transcriptional level $(44,45)$. Taken together, these data indicate a putative role for PPAR $\alpha$ in lung and skin development. Thus while ongoing clinical trials have focused on whether maternal thyroid hormone and glucocorticoid treatment accelerates lung maturation in the very premature human infant, our current studies in vitro suggest that a number of other factors, such as PPAR $\alpha$ and FXR activators, may also play important roles in accelerating epidermal and/or lung development. Because clofibrate has been shown to improve psoriatic lesions in adults (46), it is possible that topical application of PPAR $\alpha$ and FXR activators to the skin of premature infants may also be effective.

In summary, we have shown that activators of the nuclear receptors PPAR $\alpha$ and FXR accelerate epidermal barrier development, suggesting a physiologic role for these receptors in the regulation of cutaneous development. Further understanding of these signaling pathways and their interactions will undoubtedly provide valuable insights into the multifactorial regulation of epidermal development and may lead to new therapies which accelerate epidermal barrier maturation.

\section{Acknowledgments}

This study was supported by the National Institutes of Health grants AR-19098, AR-29706, PO-39448, HL-52839, AR-39639, and DK32926 (N.M. Bass), and the Medical Service Department of Veterans Affairs Medical Center.

\section{References}

1. Elias, P.M., and G.K. Menon. 1991. Structural and lipid biochemical correlates of the epidermal permeability barrier. Adv. Lipid Res. 24:1-26.

2. Downing, D.T. 1992. Lipid and protein structures in the permeability barrier of mammalian epidermis. J. Lipid Res. 33:301-313.

3. Cartlidge, P.H.T., and N. Rutter. 1992. Skin barrier function. In Fetal and Neonatal Physiology. R.A. Polin and W.W. Fox, editors. W.B. Saunders Co., Philadelphia. 569-585.

4. Harpin, V.A., and N. Rutter. 1983. Barrier properties of newborn infant's skin. J. Pediatr. 102:419-425.

5. Vernon, H.J., A.T. Lane, L.J. Wischerath, J.M. Davis, and M.A. Menegus. 1990. Semi-permeable dressings and transepidermal water loss in premature infants. Pediatrics. 86:357-362.

6. Freinkel, R.F., and T.N. Traczyk. 1985. Lipid composition and hydrolase content of lamellar granules of fetal rat epidermis. J. Invest. Dermatol. 85:295-298.

7. Aszterbaum, M., G.K. Menon, K.R. Feingold, and M.L. Williams. 1992 Ontogeny of the epidermal barrier to water loss in the rat: correlation of func- 
tion with stratum corneum structure and lipid content. Pediatr. Res. 31:308-317.

8. Hanley, K., U. Rassner, P.M. Elias, M.L. Williams, and K.R. Feingold. 1996. Epidermal barrier ontogenesis: maturation in serum-free media and acceleration by glucocorticoids and thyroid hormone but not selected growth factors. J. Invest. Dermatol. 106:404-411.

9. Aszterbaum, M., K.R. Feingold, G.K. Menon, and M.L. Williams. 1993. Glucocorticoids accelerate fetal maturation of the epidermal permeability barrier in the rat. J. Clin. Invest. 91:2703-2708.

10. Hanley, K., U. Rassner, Y. Jiang, D. Vansomphone, D. Crumrine, L. Komuves, P.M. Elias, K.R. Feingold, and M.L. Williams. 1996. Hormonal basis for the gender difference in epidermal barrier formation in the fetal rat. Acceleration by estrogen and delay by androgen. J. Clin. Invest. 97:2576-2584

11. Hanley, K., Y. Jiang, W.M. Holleran, P.M. Elias, M.L. Williams, and K.R. Feingold. 1997. Glucosylceramide metabolism is regulated during normal and hormonally-stimulated epidermal barrier development in the rat. J. Lipid Res. 38:576-584.

12. Hanley, K., Y. Jiang, C. Katagiri, K.R. Feingold, and M.L. Williams. 1997. Epidermal steroid sulfatase and cholesterol sulfotransferase are regulated during late gestation in the fetal rat. J. Invest. Dermatol. 108:871-875.

13. Mangelsdorf, D.J., C. Thummel, M. Beato, P. Herrlich, G. Schutz, K. Umesono, B. Blumenberg, P. Kastner, M. Mark, P. Chambon, and R.M. Evans. 1995. The nuclear receptor superfamily: the second decade. Cell. 83:835-839.

14. Kastner, P., M. Mark, and P. Chambon. 1995. Nonsteroid nuclear receptors: what are genetic studies telling us about their role in real life? Cell. 83:841-850.

15. Mangelsdorf, D.J., and R.M. Evans. 1995. The RXR heterodimers and orphan receptors. Cell. 83:841-850.

16. Saitou, M., S. Sugal, T. Tanaka, K. Shimouchi, E. Fuchs, S. Narumiya, and A. Kakizuka. 1995. Inhibition of skin development by targeted expression of a dominant-negative retinoic acid receptor. Nature (Lond.). 374:159-162.

17. Imakado, S., J.R. Bickenbach, D.S. Bundman, J.A. Rothnagel, P.S. Attar, X. Wang, V.R. Walczak, S. Wisniewski, J. Pote, J.S. Gordon, et al. 1995. Targeting expression of a dominant-negative retinoic acid receptor mutant in the epidermis of transgenic mice results in loss of barrier function. Genes Dev. 9:317-329.

18. Kang, S., L. Xiao-Yan, and J.J. Voorhees. 1996. Pharmacology and molecular action of retinoids and vitamin D in skin. J. Invest. Dermatol. Symposium Proceedings. 1:15-21.

19. Keller, H., C. Dreyer, J. Medin, A. Mahfoudi, K. Ozato, and W. Wahli. 1993. Fatty acids and retinoids control lipid metabolism through activation of peroxisome proliferator-activated receptor-retinoid X receptor heterodimers. Proc. Natl. Acad. Sci. USA 90:2160-2164.

20. Schoonjans, K., B. Staels, and J. Auwerx. 1996. Role of the peroxisome proliferator-activated receptor (PPAR) in mediating the effects of fibrates and fatty acids on gene expression. J. Lipid Res. 37:907-925.

21. Yu, K., W. Bayona, C.B. Kallen, H.P. Harding, C.P. Ravera, G. McMahon, M. Brown, and M.A. Lazar. 1995. Differential activation of peroxisome proliferator-activated receptors by eicosanoids. J. Biol. Chem. 270:2397523983

22. Forman, B.M. 1995. 15-Deoxy- $\Delta^{12,14}$-prostaglandin J2 is a ligand for the adipocyte determination factor PPAR $\gamma$. Cell. 83:803-812.

23. Forman, B.M., E. Goode, J. Chen, A.E. Oro, D.J. Bradley, T. Perlmann, D.J. Noonan, L.T. Burka, T. McMorris, W.W. Lamph, et al. 1995. Identification of a nuclear receptor that is activated by farnesol metabolites. Cell. 81:687-693.

24. Hurt, K., K. Hanley, M.L. Williams, and K.R. Feingold. 1995. Cutaneous lipid synthesis during late fetal development in the rat. Arch. Dermatol. Res. 287:754-760.

25. Feingold, K.R. The regulation and role of epidermal lipid synthesis. Adv. Lipid Res. 24:57-82.

26. Bocos, C., M. Gottlicher, K. Gearing, C. Banner, E. Enmark, M. Teboul, A. Crickmore, and J. Gustafsson. 1995. Fatty acid activation of peroxisome proliferator-activated receptor (PPAR). J. Steroid Biochem. Mol. Biol.
53:467-473

27. Devchand, P.R., H. Keller, J.M. Peters, M. Vazquez, F.J. Gonzalez, and W. Wahli. 1996. The PPAR $\alpha$-leukotriene B4 pathway to inflammation control. Nature (Lond.). 384:39-43.

28. Goldstein, J.L., and M.S. Brown. 1990. Regulation of the mevalonate pathway. Nature (Lond.). 343:425-430.

29. Holleran, W.M., Y. Takagi, G.M. Menon, G. Legler, K.R. Feingold, and P.M. Elias. 1993. Processing of epidermal glucosylceramides is required for optional mammalian cutaneous permeability barrier function. J. Clin. Invest. 91: $1656-1664$.

30. Correll, C.C., L. Ng, and P.A. Edwards. 1994. Identification of farnesol as the non-sterol derivative of mevalonic acid required for the accelerated degradation of 3-hydroxy-3-methylglutaryl-coenzyme A reductase. J. Biol. Chem. 269:17390-17393.

31. Weinberger, C. 1996. A model for farnesoid feedback control in the mevalonate pathway. Trends Endocrinol. Metab. 7:1-6.

32. Voziyan, P.A., C.M. Goldner, and G. Melnykovch. 1993. Farnesol inhibits phosphatidylcholine biosynthesis in cultured cells by decreasing cholinephosphotransferase activity. Biochem. J. 295:757-762.

33. Haug, J.S., C.M. Goldner, E.M. Yazlovitskaya, P.A. Voziyan, and G.M. Melnykovych. 1994. Directed cell killing (apoptosis) in human lymphoblastoid cells incubated in the presence of farnesol: effect of phosphatidylcholine. Biochim. Biophys. Acta. 1223:133-140.

34. Roullet, J., H. Xue, J. Chapman, P. McDougal, C.M. Roullet, and D.A McCarron. 1996. Farnesyl analogues inhibit vasoconstriction in animal and human arteries. J. Clin. Invest. 97:2384-2390.

35. Holt, P.J., J. Lazarus, and R. Marks. 1977. The epidermal response to changes in thyroid status. J. Invest. Dermatol. 68:299-301.

36. Fell, H.B., and E. Mellenby. 1953. Metaplasia produced in cultures of chick ectoderm by high vitamin A. J. Physiol. 19:470-488.

37. Elias, P.M., and D.S. Friend. 1976. Vitamin A-induced mucous metaplasia: an in vitro system for modulating tight and gap junction differentiation. $J$. Cell Biol. 68:173-188.

38. Pillai, S., D.D. Bikle, and P.M. Elias. 1988. Vitamin D and epidermal differentiation: evidence for a role of exogenously produced vitamin D metabolites in keratinocyte differentiation. Skin Pharmacol. 1:149-160.

39. Regnier, M., and M. Darmon. 1991. 1,25-Dihydroxyvitamin D3 stimulates specifically the last steps of epidermal differentiation of cultured human keratinocytes. Differentiation. 47:173-188.

40. Hodson, W.A. 1992. Normal and abnormal structural development of the lung. In Fetal and Neonatal Physiology. R.A. Polin and W.W. Fox, editors. W.B. Saunders Co., Philadelphia. 771-782.

41. Schellhase, D.E. P. A. Emrie, J.H. Fisher, and J.M. Shannon. 1989. Ontogeny of surfactant apoproteins in the rat. Pediatr. Res. 26:167-174.

42. Ballard, P.L. 1989. Hormonal regulation of pulmonary surfactant. Endocrinol. Rev. 10:165-178.

43. Fringes, B., K. Gorgas, and A. Reith. 1988. Clofibrate increases the number of peroxisomes and of lamellar bodies in alveolar cells type II of the rat lung. Eur. J. Cell Biol. 46:136-143.

44. Lemberger, T., B. Staels, R. Saladin, B. Desvergne, J. Auwerx, and W. Wahli. 1994. Regulation of the peroxisome proliferator-activated receptor $\alpha$ gene by glucocorticoids. J. Biol. Chem. 269:24527-24530.

45. Steineger, H.H., H.N. Sorensen, J.D. Tugwood, S. Skerede, O. Spydevold, and K.M. Gautvik. 1994. Dexamethasone and insulin demonstrate marked and opposite regulation of the steady-state mRNA level of the peroxisomal proliferator-activated receptor (PPAR) in hepatic cells. Eur. J. Biochem. 225:967-974.

46. Imamura, T., I. Takata, M. Ogasawara, Y. Matsutani, T. Yamamoto, and C. Asagami. 1991. Clofibrate treatment of psoriasis with hypertriglycemiaclinical, histological and laboratory analysis. Nippon Hifuka Gakkai Zasshi. 101:623-628. 